\title{
Fetal Diagnosis and Therapy: Farewell as Editor-in-Chief
}

\section{Eduard Gratacós}

ICGON and BCNatal, Barcelona Center for Maternal-Fetal and Neonatal Medicine (Hospital Clínic and Hospital Sant Joan de Deu), University of Barcelona, and Center for Biomedical Research on Rare Diseases (CIBER-ER), Barcelona, Spain

I am writing this brief editorial on the occasion of handing over the Editor-in-Chief position of the journal to Prof. Edgar Hernandez-Andrade, after serving 13 years in this position. I must first express my thanks to the editorial office and its always very efficient and kind office staff, with a particular recognition to Ms. Patricia Bachmann, one of the true assets of this journal. A special recognition also to Prof. Wolfgang Holzgreve, my predecessor, and to Mr. Thomas Nold from Karger, for offering me the place back in 2008. While I was initially not particularly inclined, my conversations with Mr. Nold were extremely pleasant, and he very skillfully managed to convince me to take the position, in which I eventually have remained longer than I expected. I must express my profound gratitude to all Associate Editors, all of them renowned academics in their fields and most of them joining during my term as Editor-in-Chief, for accepting to be part of the editorial team and provide their time, expertise and honest insights in the selection and evaluation of submissions. Many thanks as well to the members of the Editorial Board and to the countless expert reviewers who gave us part of their valuable time to assist in the peer review of manuscripts. And of course, my deepest thanks to all authors, the clinicians and researchers who trusted us submitting their work over these years.

karger@karger.com www.karger.com/fdt

Karger"
C 2022 The Author(s)

Published by S. Karger AG, Basel

This is an Open Access article licensed under the Creative Commons Attribution-NonCommercial-4.0 International License (CC BY-NC) (http://www.karger.com/Services/OpenAccessLicense), applicable to the online version of the article only. Usage and distribution for commercial purposes requires written permission.
Fetal Diagnosis and Therapy was founded as Fetal Therapy 35 years ago, and it quickly found a place among the journals dedicated to the rapidly growing field of fetal medicine and therapy. When the current editorial team took over from previous editors in 2008, the journal was already well positioned in the ranking of obstetrics and gynecology journals. We decided to promote high-quality reviews and original research over case reports, aiming at increasing the Impact Factor (IF). The IF is a highly criticized index, but eventually all researchers look first and foremost at the IF at the time of submitting their research to a journal. This strategy entailed increasing the quality threshold for publishing in the journal, and consequently decreasing the acceptance rates, which over the years have stabilized at about $20-25 \%$. Being Editor of a journal is not the quickest way to make friends among colleagues. As a researcher myself, I understand the frustration that authors feel with a rejection, and this is the hardest part of the job. I truly apologize to the many authors who saw their papers declined for publication. Another critical goal was persuading renowned research groups to consider our journal as a suitable place for publishing their data. It was hard to wait for the IF to rise, but after a transitional period, the strategy of promoting original research and quality eventually proved to be very suc-
Correspondence to:

Eduard Gratacós, gratacos@fetalmedicinebarcelona.org 
cessful. The IF of the journal has risen from 0.8 to 2.58 in 12 years, a 3.2-fold increase, which is higher than the average "inflation rate" of the IF for journals in the same field. I believe we can proudly say that at this moment the journal is very well consolidated among the main journals in the field of fetal medicine and therapy.

During these years we decided to focus essentially on clinical fetal medicine, although the journal has been open to publish selected studies reporting experimental and/or more basic research. The future orientation of the journal will be decided by the new Editor-in-Chief. I am absolutely convinced that Fetal Diagnosis and Therapy will continue increasing its relevance and attracting orig- inal research and high-quality reviews to help advancing our field. Fetal medicine will only increase exponentially over future years, and will incorporate, as most other areas in human health, new med-tech solutions, artificial intelligence and molecular therapies, among others. The societal demands for a high-quality fetal medicine will also foster the development of new research leading eventually to new clinical solutions. Fetal Diagnosis and Therapy will remain one of the important journals to disseminate all this research. It has been a great honor and privilege to be Editor-in-Chief of Fetal Diagnosis and Therapy. Eduard Gratacós, Barcelona 